\title{
The Impact of Pictograph-Based Education on Knowledge, Attitude, Self-Care, Fasting Blood Glucose and HbA1c Levels in Type 2 Diabetic Patients in Kerman
}

\begin{abstract}
Background and objective: Education can play an important role in the management of chronic diseases such as diabetes. This study was conducted to determine the impact of pictograph-based education on knowledge, attitude, selfcare, fasting blood glucose and HbA1c among patients with type 2 diabetes. Materials and methods: This study was a randomized controlled trial (RCT) on 100 patients with type 2 diabetes referred to diabetes clinics in Kerman city. The participants were randomly divided into intervention and control groups with 50 patients in each group. In the intervention group, pictograph-based training was presented in the form of slides and posters along with lectures, but in the control group lectures without pictographs was presented. The data were collected and analyzed using chi-square tests, independent t-test, paired t-test Wilcoxon and Mann-Whitney U through SPSS16.

Results: The mean score of total self-care significantly increased in the intervention group ( $p<0.0001$ ). The self-care components of foot care and blood glucose monitoring significantly improved in the intervention group, too. Fasting glucose and $\mathrm{HbA} 1 \mathrm{c}$ decreased in both groups and knowledge in both groups improved after the intervention, but attitude only increased in the intervention group.

Conclusion: Considering the significant role of pictographs in learning health instructions, it seems that education using pictographs can promote self-care behaviors among diabetic patients who are mainly old and/or with low literacy. Paper Type: Research Article.

Keywords: Knowledge, Attitude, Self-care, Pictographs, Educational intervention, Type 2 diabetes, Kerman.
\end{abstract}

Citation: Nazari F, Khanjani N, Mahmoodi MR, Fadakar MM. The impact of pictograph-based education on knowledge, attitude, self-care, fasting blood glucose and $\mathrm{HbA} 1 \mathrm{c}$ levels in type 2 diabetic patients in Kerman. Iran J Health Educ Health Promot. Autumn 2016;4(3): 194-204.

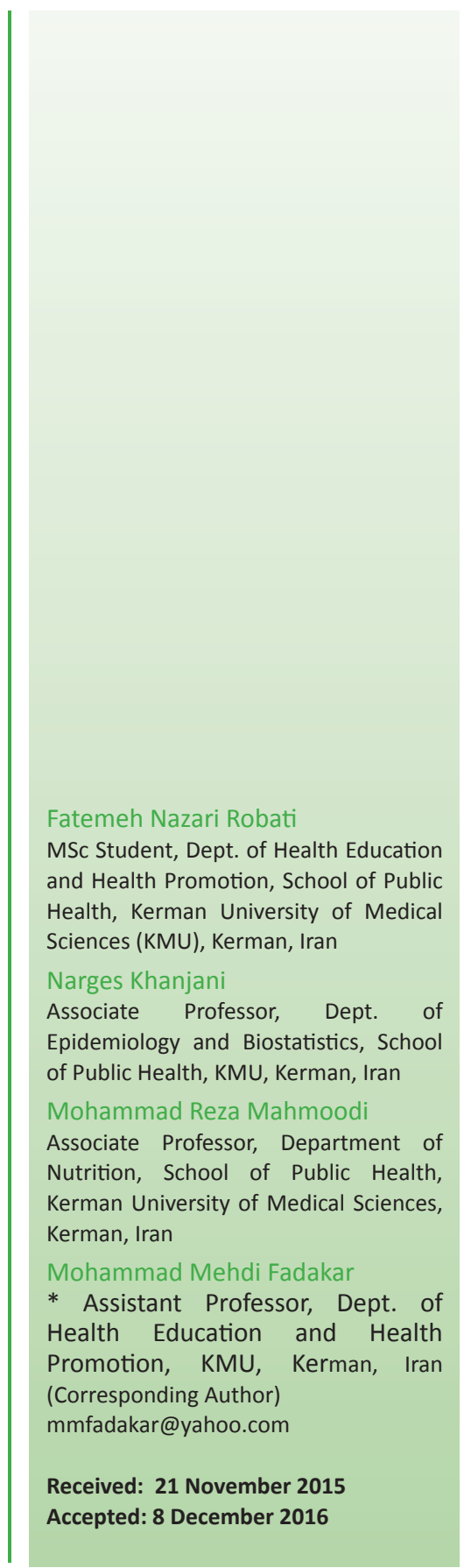


فاطمه نظرى رباطى دانشجوى كارشناسىارشد آموزش بهداشت و ارتقاء

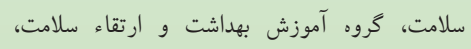

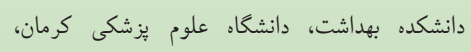
كرمان، ايران

$$
\text { نز خس خانجانى }
$$
دانشيار كروه آمار و ابيدميولوزى، دانشكده بهداشت، دانشكا، علوم يزشكى كرمان، كرمان، ايران

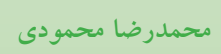

دانشيار كروه تغذيه، دانشكده بهداشت، دانشكا، علوم محرى يز يزكى كرمان، كرمان، ايران

محمدمهدى فداكار

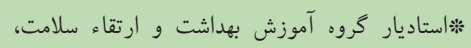

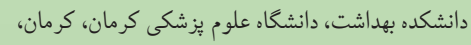
ايران (نويسنده مسئول) mmfadakar@yahoo.com

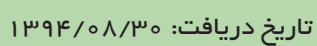

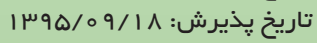

\section{O}

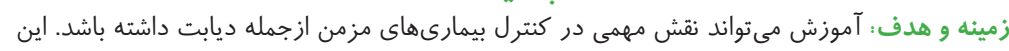

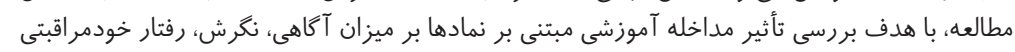

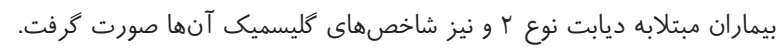

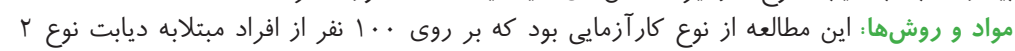

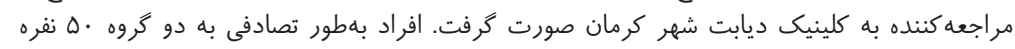

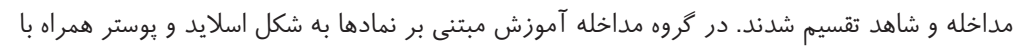

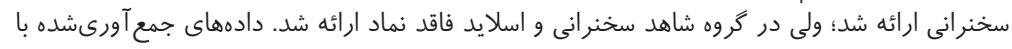

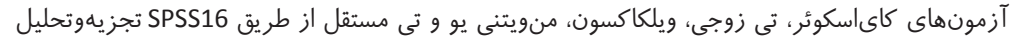

شدند.

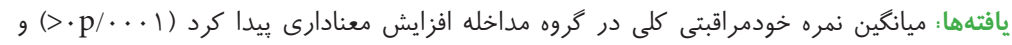

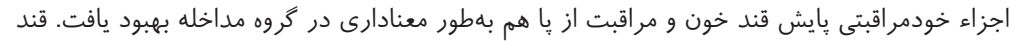

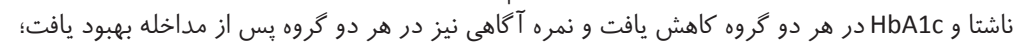

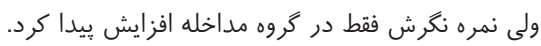

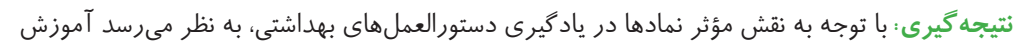

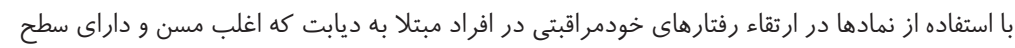

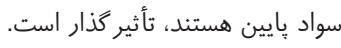

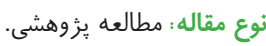

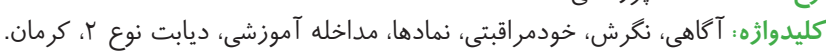

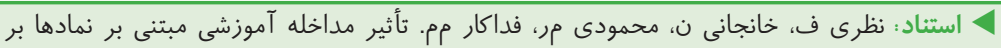

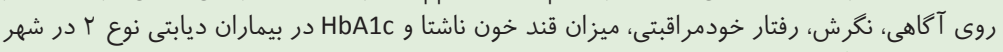

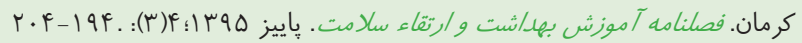


وجود برنامه آموزشى يكى از راههاى اساسى در تغيير سبك

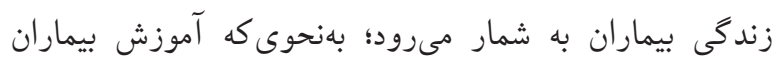
منجر به كاهش عوامل خطر و افزايش رفتارهاى سالم در ايشان

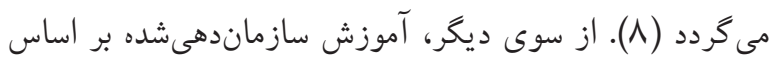

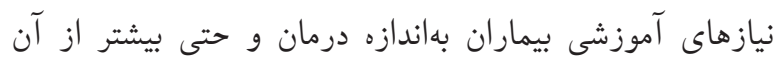

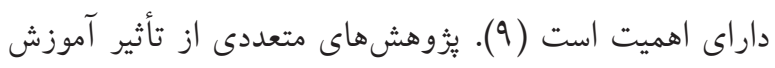
بر بهبود آكاهى، نكرش و عملكرد، كاهش قند خون و درنتيجه

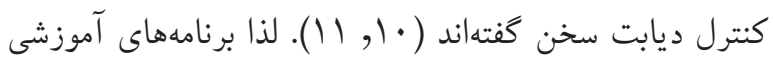
ديابت بايد راهبردهاى افزايش آكاهى و نكرش بيماران، بهبود

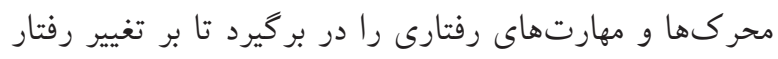

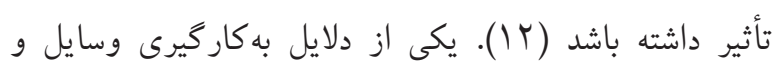
مواد آموزشى نقش متفاوتى است كه حواس در يادكيرى افراد دارند. بهطورى كه بينايى با هD٪ بيشترين نقش را بين حواس

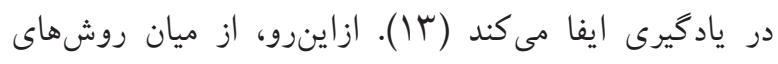

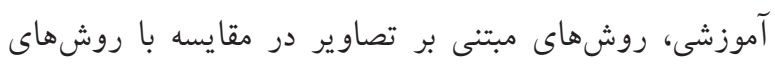

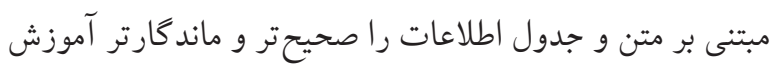

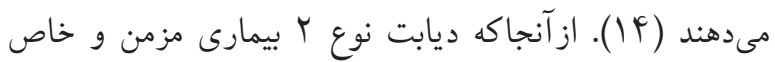

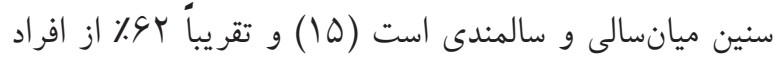

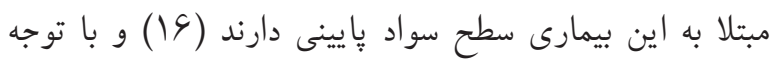

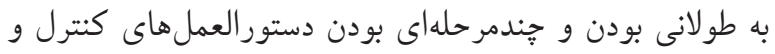

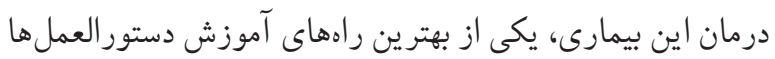

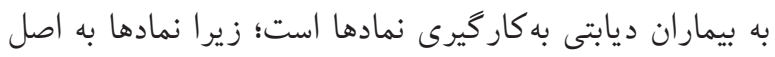

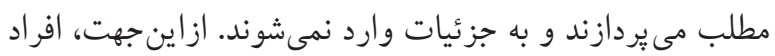

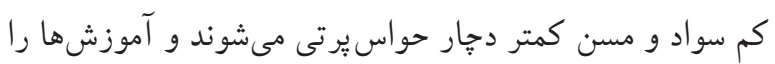
بهتر و كامل تر درك مى كنند (IV) ازاينرو، با توجه به اينكه ديابت از شيوع بالايى برخوردار

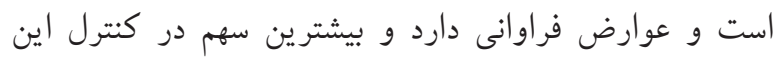

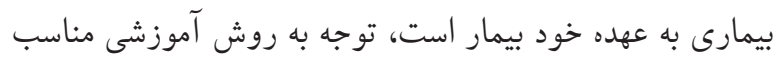

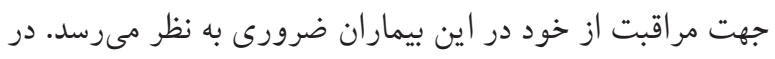

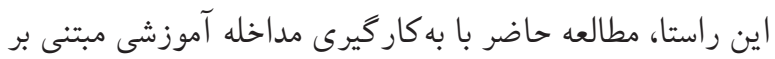

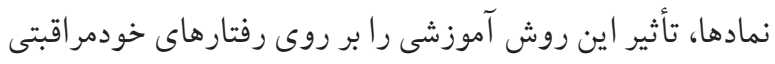

ديابت از شايعترين بيمارىهاى مزمن و متابوليك است كه بهصورت يك إيدمى جهانى در يـى تغيير در شيوه زندكى مردم

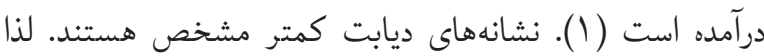
اغلب جندين سال پِ از دركيرى تشخيص داده مىشوند. اين بيمارى ناشى از توليد نشدن انسولين توسط پانكراس يا مؤثر

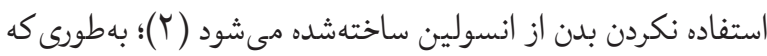
ديابت نوع r، كه قبلاً (اديابت بزرگسالان)) يا (اديابت غيروابسته

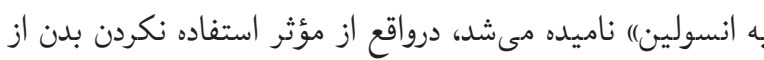

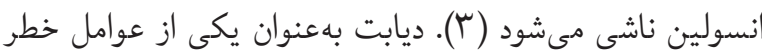
بيمارى كرونرى قلب و بروز انفاركتوس قلبى و درنهايت ناتوانى و

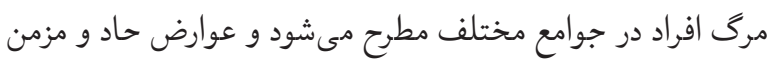

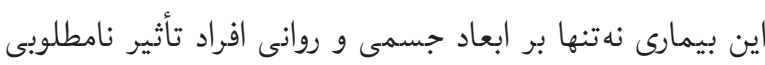

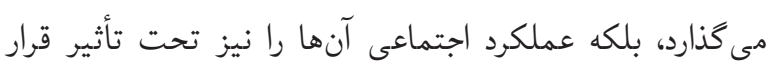
مى دهد (F). (F). طبق بيشبينى سازمان جهانى بهداشت ديابت هفتمين عامل

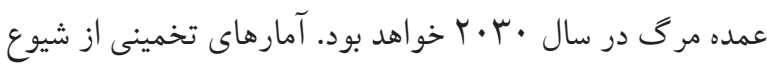

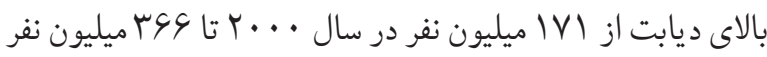

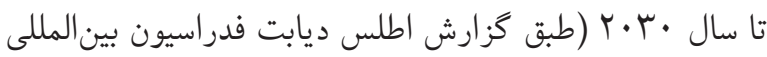
ديابت') در سراسر جهان خبر مىدهند بهنحوى كه اين بيمارى (برى

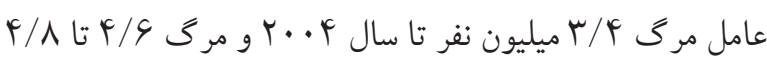

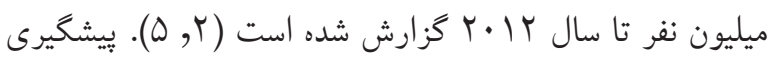

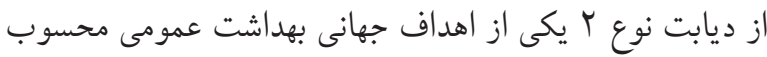

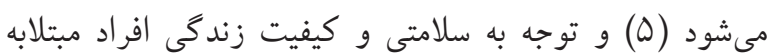

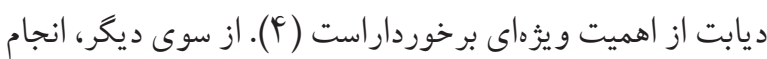
مداخلات بهداشتى در افراد داراى بيمارى مزمن از جمله ديابت بهورديت

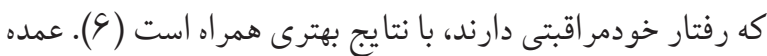

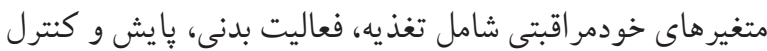

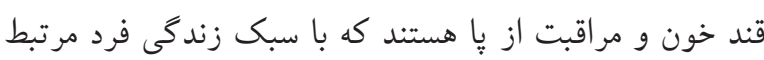
هستند (V) (V). (V) 


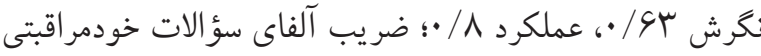

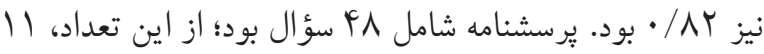

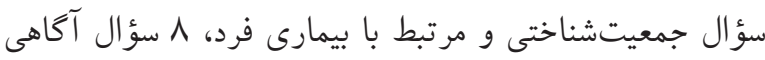
با گزينه بلى يا خير و كز ينه صحيح (صفر تا 1 امتياز)، 9 سؤال

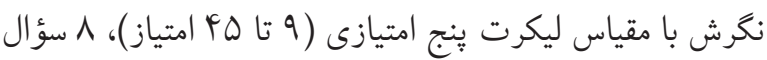

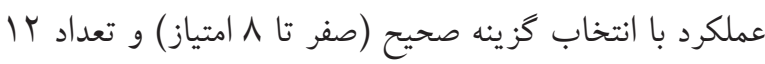
سؤال مربوط به خودمراقبتى با مقياس ليكرت هفت امتيازى

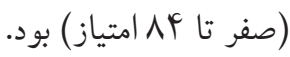
قبل از شروع مداخله ميزان قند خون ناشتا' و همو كلوبين

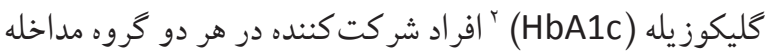
و شاهد با معرفى به آزما يشعاه واحد اندازه كيرى شد. سيس افر اد

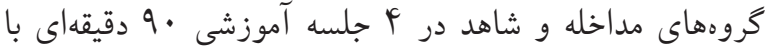

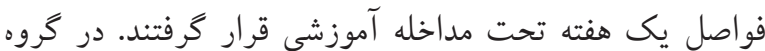
مداخله آموزش مبتنى بر نمادها به شكل اسلايد و يوستر همراه با سخنرانى ارائه شد؛ ولى در گروه شاهد سخنرانى و اسلايد فاقد برد نمادها ارائه شد. نمادهاى كرافيكى “موردنظر بر اساس اجزاى خودمر اقبتى افراد ديابتى، كه در مطالعه كيفى حسنى و همكاران

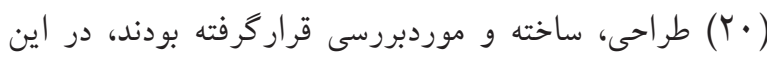

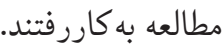
نحوه بر گزارى و مباحث مطرحشده در جلسات آموزشى در هر دو كروه بهاينترتيب بود: در جلسه اول خودمراقبتى و تغذيه صحيح افراد ديابتى، در جلسه دوم خودمراقبتى و مصرف صحيح

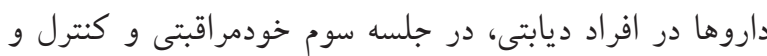
پايش منظم قند خون افراد ديابتى و در جلسه جهارم خودمر اقبتى و فعاليت بدنى و مراقبت روزانه از پا در افراد ديابتى. در هر جلسه

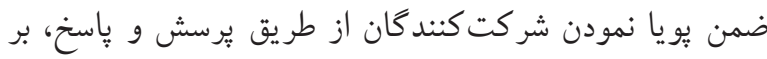
ارتباط و مشاوره منظم با يزشك متخصص و ساير مراقبين

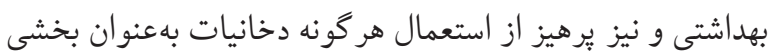

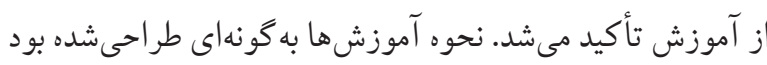

1. Fasting blood sugar (FBS)

2. haemoglobin $\mathrm{A} 1 \mathrm{c}(\mathrm{HbA} 1 \mathrm{c})$

3. pictographs
بيماران ديابتى نوع † شهر كرمان موردبررسى قرار داد.

مو اد و روش هما

اين مطالعه به روش مطالعه مداخلهاى انجام شد. مطالعه بر روى ..1.

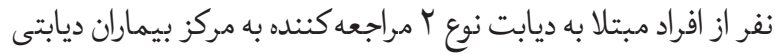
شهر كرمان در سال سوس| صورت گرفت. از بين افراد واجد شرايط ورود به مطالعه كه يس از اطلاعرسانى از طريق آن مركز و بهطور داوطلبانه با اعلام رضايت شفاهى مشخص كرديدند، حجم نمونه با توجه به مطالعه طُل و همكاران (9) تعيين شد. بر اين اساس، امتياز

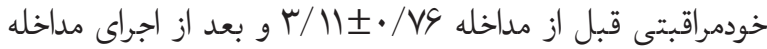

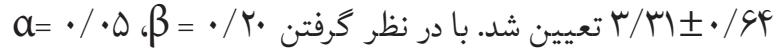
و با استفاده از فرمول مقايسه ميانگينها تعداد 4 ن نفر از هر كروه مناسب بود؛ كه در اين مطالعه تعداد •له نفر در هر گروه و مجموعاً •l نفر وارد مطالعه شدند. افراد با تخصيص تصادفى بهوسيله اعداد تصادفى توليدشده با اكسل به دو گروه •ه نفره مداخله و شاهد تقسيم شدند. معيارهاى ورود به مطالعه عبارت بودند از: تمايل به همكارى، سن فT تا •و سال، داشتن توان جسمى و ذهنى جهت پِاسخكويى به

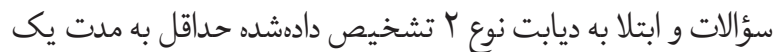
ماه. معيارهاى خروج از مطالعه نيز شامل نداشتن معيارهاى فوق و ابتلا به انواع ديخر ديابت نظير ديابت نوع ا و يا ديابت باردارى، ابتلابه اختلالات بينايى، نوروياتى، فراموشى و يا عدم يادخيرى بودند.

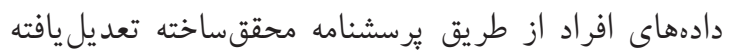

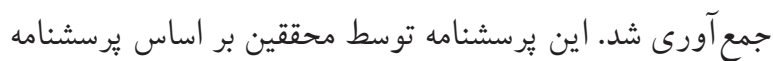
استاندارد توبرت استفادهشده در مطالعه طل و همكاران (1) و يرسشنامه KAP استفادهشده در مطالعه كودرزى و همكاران (19) طراحى گرديد. در هر دو مطالعه يرسشنامه بهصورت ترجمهشده فارسى مورداستفاده قرار كرفته بود. يرسشنامه تعديل يافته مذكور

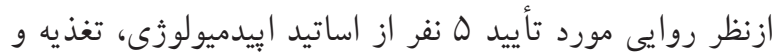
آموزش بهداشت قرار گرفت و يس از تأييد پايايى با استفاده

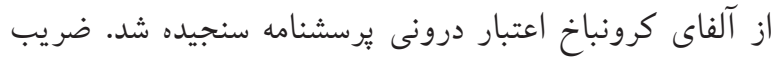
آلفاى بخشهاى سؤالات KAP عبارت بودند از: آكاهى 4 / •، 


\begin{tabular}{|c|c|c|c|}
\hline \multirow{5}{*}{$\cdot / F \Delta$} & \multicolumn{3}{|c|}{ ت تحصيلات } \\
\hline & $\wedge(\mid \&)$ & $9(\mid \Lambda)$ & 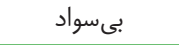 \\
\hline & MI (SY) & $r \xi(F \wedge)$ & ابتدايى و راهنمايى \\
\hline & $9(\backslash \Lambda)$ & $\operatorname{lr}(r \wedge)$ & دبيرستان و دييلم \\
\hline & $r(F)$ & $\mu(\varphi)$ & دانشكاهى \\
\hline \multirow{5}{*}{$\cdot / 1 r$} & \multicolumn{3}{|c|}{ درامد خانواده (' هزار تومان) } \\
\hline & $10(10)$ & $r \Delta(r \Delta)$ & كمتر از ·. \\
\hline & 出( & $Y Y(Y Y)$ & 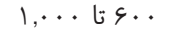 \\
\hline & $F(F)$ & $\mu(r)$ & $r, \cdots(1, \cdots$ \\
\hline & . & . & $+\cdots r, \cdot$ \\
\hline
\end{tabular}

آزمون كاى اسكوئر؛

با مقايسه زوجى دو كانه مشخص كرديد كه نمره آكاهى

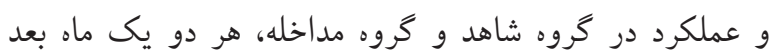

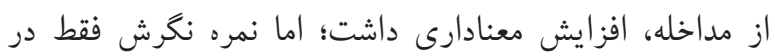

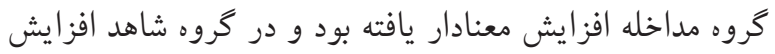
معنادارى ييدا نشده بود (جدول Y). مقايسه سطح خونى FBS

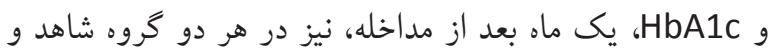

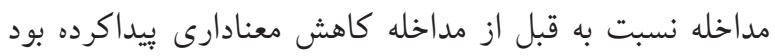

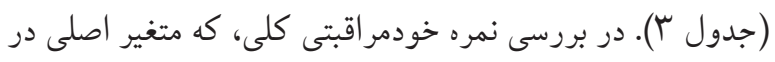

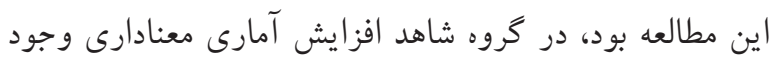
نداشت ولى در كروه مداخله افزايش آمارى معنادارى مشاهده كرديد.

همجنين از بين اجزاء خودمراقبتى، يكماه پِ از مداخله،

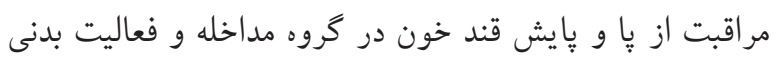

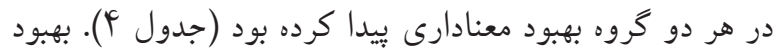

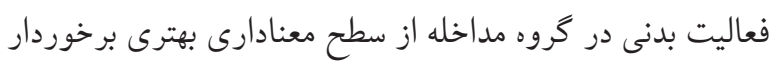

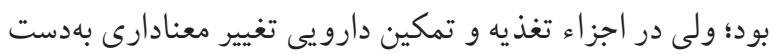

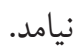

كه افراد با محتواى آموزشى تأييدشده بر طبق منابع معتبر كشورى و دانشگاهى بهويزه در زمينه تغذيه و فعاليت بدنى آشنا مي شيدند.

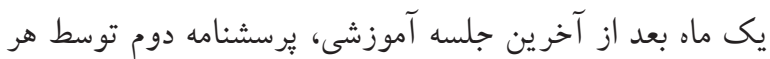

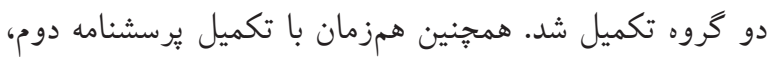

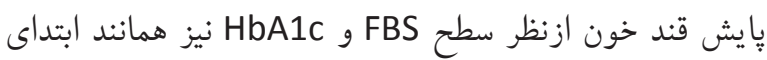

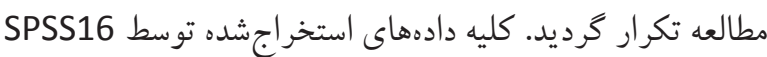
ثبت و مورد تجزيهوتحليل آمارى قرار كرفت. از طريق آزمون

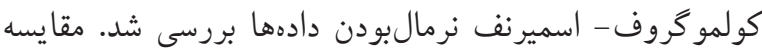

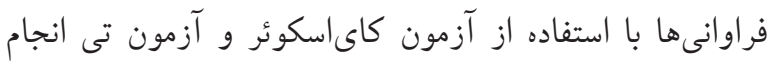

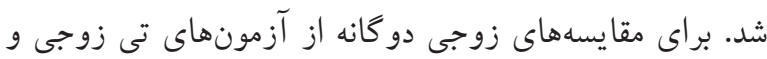

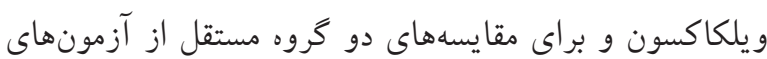
تى مستقل و منويتنى يو استفاده شد.

يافتنه

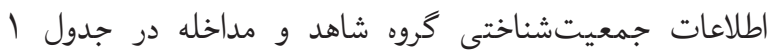

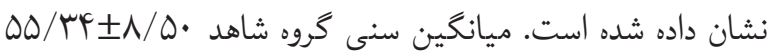
و ميانگين سنى گروه مداخله

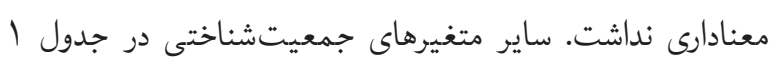
نشان دادهشدهاند.

جدول ا. فراوانى (و فراوانى نسبى) ويثَى پايه افراد تحت مطالعه

\begin{tabular}{|c|c|c|c|}
\hline p-value & $\begin{array}{c}\text { كروه مداخله } \\
(\mathbf{n}=\Delta \cdot)\end{array}$ & $\begin{array}{c}\text { كروه شاهد } \\
(\mathbf{n}=\Delta \cdot)\end{array}$ & متغير هاى زمينهاى \\
\hline \multirow{3}{*}{.19} & \multicolumn{3}{|c|}{ جنسيت } \\
\hline & $\wedge(19)$ & $1 \cdot(r \cdot)$ & مرد \\
\hline & $\operatorname{Fr}(\lambda F)$ & $r \cdot(\Lambda \cdot)$ & زن \\
\hline \multirow{5}{*}{.$/ 94$} & \multicolumn{3}{|c|}{ تأهل } \\
\hline & $1(r)$ & $1(r)$ & مجرد \\
\hline & $r \Delta(q)$. & $F F(\Lambda \Lambda)$ & متأهل \\
\hline & $r(\Lambda)$ & $\Delta(1 \cdot)$ & بيوه \\
\hline & . & . & مطلقه \\
\hline \multirow{3}{*}{.194} & \multicolumn{3}{|c|}{ شغل } \\
\hline & $9(11)$ & $1 \cdot(r \cdot)$ & شاغل \\
\hline & rI(Ar) & $r \cdot(\lambda \cdot)$ & غير شاغل \\
\hline
\end{tabular}


جدول r. مقايسه ميانگَين نمرات آكَاهى، نگَرش و عملكرد در گروههاى شاهد و مداخله قبل و بعد از آزمون

\begin{tabular}{|c|c|c|c|c|c|}
\hline ن آزمون & مقايسه قبل و يك ماه بعد از (p- value ماخ & (ميانگين ذ بانحر افمعيار) & 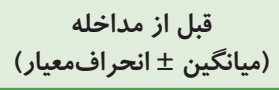 & مروههاى & متغير \\
\hline \multirow{2}{*}{ ويلكاكسون } & $>\cdot / \cdots 1$ & $9 / 99 \pm \cdot / 1 \Lambda$ & $\Delta / \Lambda \cdot \pm I / r \mid$ & شاهد & \multirow{2}{*}{ آكاهى } \\
\hline & $\cdot / \mu r$ & $s / \cdot V \pm \cdot / \Lambda \mid$ & $\varsigma / \cdot \wedge \pm 1 / \cdot f$ & مداخله & \\
\hline & &.$/ 99$ & $\cdot / \mu \wedge$ & \multicolumn{2}{|c|}{ منويتنى يو (p-value) } \\
\hline \multirow{2}{*}{ آزمون تى زوجى } & .101 & $\mu \mu / \gamma \gamma \pm \psi / \mu \Lambda$ & $r \mu / V \cdot \pm r / V \Delta$ & شاهد & \multirow{2}{*}{ 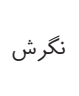 } \\
\hline &.$/ \cdot 1$ & $r s / \uparrow q \pm r / \mathscr{A} s$ & $r F / V \wedge \pm F / \Delta \varphi$ & مداخله & \\
\hline & &.$/ .1$ & $\cdot / r F$ & \multicolumn{2}{|c|}{ آزمون تى مستقل (p-value) } \\
\hline \multirow{2}{*}{ ويلكاكسون } & $>\cdot / \cdots 1$ & $s / r \Delta \pm 1 / F q$ & $\Delta / 19 \pm 1 / 9 \vee$ & 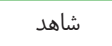 & \multirow{2}{*}{ عملكرد } \\
\hline & $>\cdot / \cdots 1$ & $q / 4 F \pm 1 / \Delta q$ & $\uparrow / \wedge \Lambda \pm 1 / \vee \wedge$ & مداخله & \\
\hline & & $\cdot / 4 q$ & $\cdot /$ Ar & \multicolumn{2}{|c|}{ منويتنى يو (p-value) } \\
\hline
\end{tabular}

جدول سا. مقايسه ميانغين نمرات شاخصهاى كَليسميك در گَروههاى شاهد و مداخله قبل و بعد از آزمون

\begin{tabular}{|c|c|c|c|c|c|}
\hline نوع آزمون & $\begin{array}{c}\text { مقايسه قبل و يك ماه بعد از مداخله } \\
\text { (p- value) }\end{array}$ & ميانكين 土ـ انحراف افمعيار & ميانكين 土 انحراف مداخله & مدروهاى - مداخله & متغير \\
\hline \multirow{2}{*}{ تى زوجى } &.$/ \cdot 1$ & $N / 1 \Delta \pm 1 / \Delta r$ & $N / P F \pm 1 / r q$ & شاهد & \multirow{2}{*}{$\mathrm{HbAlc}$} \\
\hline & $\cdot / \cdot r$ & $\Lambda / \cdot r \pm I / \wedge V$ & $\Lambda / r q \pm 1 / \Lambda \Lambda$ & مداخله & \\
\hline & & $\cdot / \mathrm{V} 4$ & $\cdot / \mathrm{V}$ & \multicolumn{2}{|c|}{ آزمون تى مستقل (p-value) } \\
\hline \multirow{2}{*}{ تى زوجى } & $\cdot / \cdot r$ & $|S| / \Delta \cdot \pm \Delta \Delta / \wedge \varphi$ & $19 r / G F \pm S V / F F$ & شاهد & \multirow{2}{*}{ FBS } \\
\hline &.$/ .1$ & $G F \mid / r r \pm F q / / F$ & $19 r / 9 \cdot \pm \Delta N / r$ & مداخله & \\
\hline & & .119 &.$/ .1$ & \multicolumn{2}{|c|}{ آزمون تى مستقل (p-value) } \\
\hline
\end{tabular}

جدول عا. مقايسه ميانگين نمرات خودمراقبتى در گروههاى شاهد و مداخله قبل و بعد از آزمون

\begin{tabular}{|c|c|c|c|c|c|}
\hline ن آزمون & $\begin{array}{c}\text { p- value } \\
\text { (مقايسه قبل و يكماه بعد از مداخله) }\end{array}$ & ميانكين 土 انحراه بعد افمعيله & ميانگين 土 انحرافلمعيار & مروههاى & متغير \\
\hline \multirow{2}{*}{ تى تى تست زوجى } &.$/ 91$ & $\mid N / F \Delta \pm \Delta / \uparrow$ & $\mid \Lambda / r q \pm r / \wedge r$ & شاهد & \multirow{2}{*}{ ت تغذيه } \\
\hline & $\cdot /$ A & $r \cdot / 19 \pm r / s$ & $r \cdot / \cdot r \pm \Delta / r V$ & مداخله & \\
\hline & & $\cdot / 1$ & $\cdot / 1 \wedge$ & \multicolumn{2}{|c|}{ آزمون تى مستقل (p-value) } \\
\hline \multirow{2}{*}{ 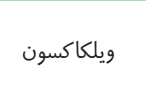 } & $<\cdot / \cdots 1$ & $V / \Delta V \pm F / V \Lambda$ & $S / \Delta F \pm F / A V$ & 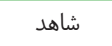 & \multirow{2}{*}{ 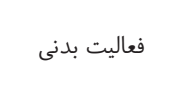 } \\
\hline & $<\cdot / \cdots \cdot \mid$ & $q / F r \pm r / r v$ & $\varsigma / \cdot \wedge \pm \Delta / \Upsilon_{q}$ & 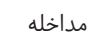 & \\
\hline & &.$/ .9$ & $\cdot 10$ & \multicolumn{2}{|c|}{ من ويتنى يو (p-value) } \\
\hline \multirow{2}{*}{ 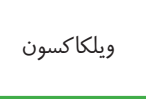 } & $\cdot / I V$ & $\mid \varepsilon \pm \Delta / r V$ & $\mid q / \Delta s \pm \Delta / s q$ & 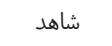 & \multirow{2}{*}{ 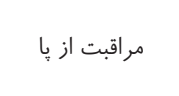 } \\
\hline & $\cdot / \cdots \wedge$ & $19 / \Lambda r \pm r / \mu r$ & $\mid r / 9 r \pm \Delta / \wedge \Delta$ & 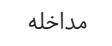 & \\
\hline & & $\cdot 10$ & $\cdot / 0$ & \multicolumn{2}{|c|}{ من ويتنى يو (p-value) } \\
\hline \multirow{2}{*}{ ويلكاكسون } & $\cdot / V r$ & $11 / V \Delta \pm \Psi / r r$ & $\mid r / \mu r \pm \mu / r r$ & شاهد & \multirow{2}{*}{ 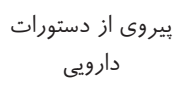 } \\
\hline & 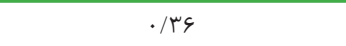 & $\mid r / r s \pm r / r$ & $\mid r / V \pm r / s V$ & مداخله ل & \\
\hline & & $\cdot / \cdot v$ & $\cdot / 1$ & \multicolumn{2}{|c|}{ من ويتنى يو (p-value) } \\
\hline \multirow{2}{*}{ ويلكاكسون } & $\cdot / r$ & $r / F \backslash \pm r / \mid F$ & $1 / \Lambda \cdot \pm r / 19$ & 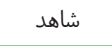 & \multirow{2}{*}{ كنترل قند خون } \\
\hline & $<\cdot / \cdot 1$. & $r / \Delta r \pm r / r \Lambda$ & $1 / \mathscr{F} \wedge \pm r / \cdot \Delta$ & 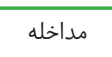 & \\
\hline & &.$/ 9$ & $\cdot / \uparrow^{q}$ & \multicolumn{2}{|c|}{ من ويتنى يو (p-value) } \\
\hline \multirow{2}{*}{ تى ت تست زوجى } & $\cdot / r 1$ & $\Delta F / \cdot r \pm \mid F / q F$ & $\Delta 1 / V \Delta \pm I Y / Q F$ & 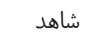 & \multirow{2}{*}{ 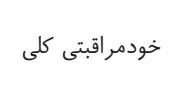 } \\
\hline & $>\cdot / \cdots 1$ & SI/FF $\pm \| 1 /$ Ar & $\{q / r \wedge \pm 1 \cdot / F \wedge$ & 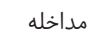 & \\
\hline & &.$/ \cdots 9$ & $\cdot / \pi r$ & \multicolumn{2}{|c|}{ آزمون تى مستقل (p-value) } \\
\hline
\end{tabular}


مطالعه حاضر نشان داد كه ميانگين نمره كلى خودمر اقبتى ڤِ از

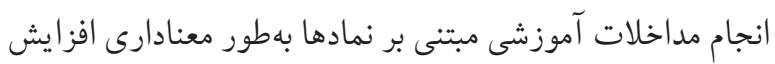

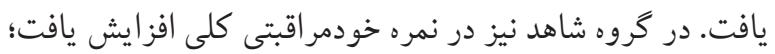

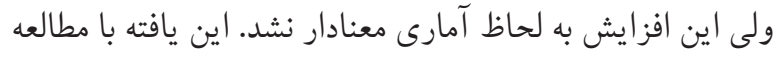

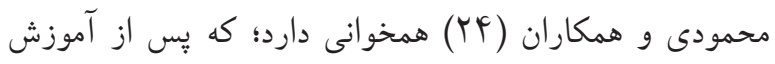

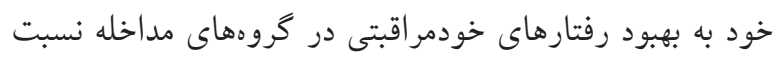
به گروه شاهد دست يافتند. هرجند در اين مطالعه تفاوتى بين نمره

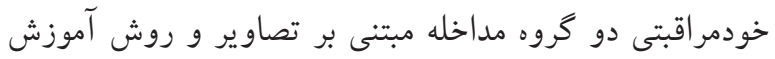

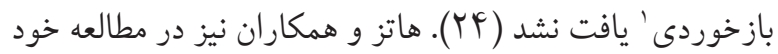

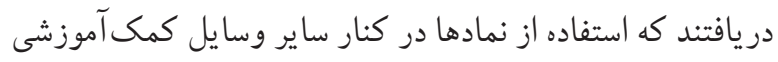
مىتواند تا هیی يادآورى دستورالعملهاى ارائهشده را افزايش دهد (YO). هاتز در مطالعهاى ديكر نشان داد كه استفاده از

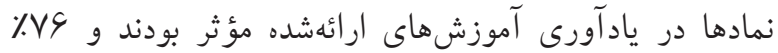

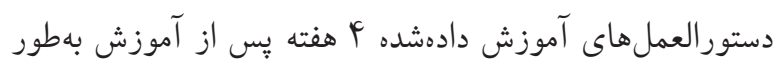
صحيح توسط فراخيران يادآورى شدند (Y) (Y). مطالعات مختلف نشاندهنده سطح سواد بهداشتى پايين بيماران در نقاط مختلف دنيا است. لذا اطلاعات بهداشتى بايد

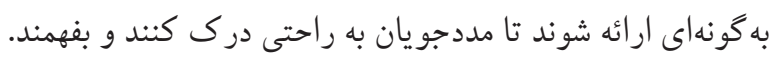

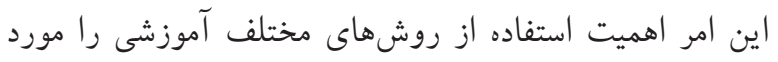

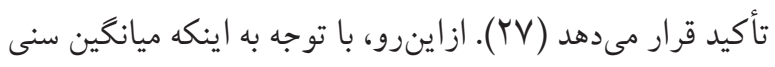
افراد شركت كننده در مطالعه حاضر در هر دو كروه نسبتاً بالا

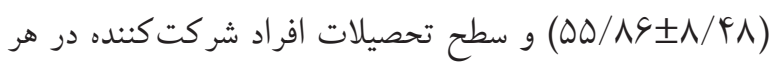

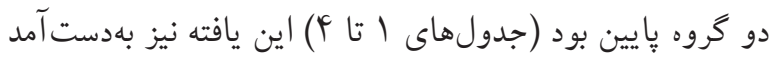

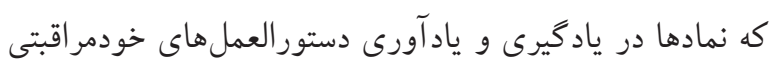
در بيماران ديابتى كم سواد و سن بالا هم مؤثر است.

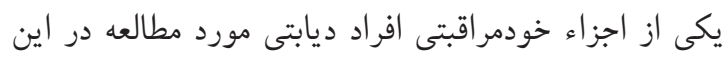

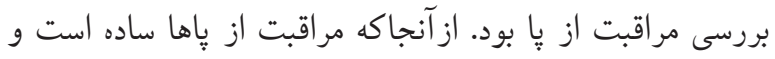

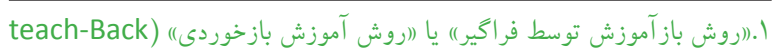

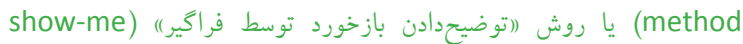
(method

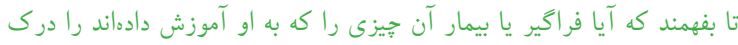

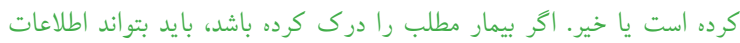
بهدست آورده را به سهولت توضيح يا ياد دهد.

آكاهى و نكخرش دو عامل مؤثر بر عملكرد بيماران ديابتى هستند. بنابراين، افرادى كه آكاهى كافى در مورد بيمارى و عوارض آن آن ندارند

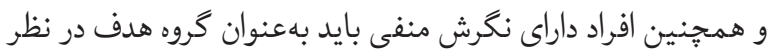

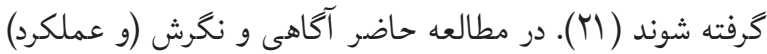

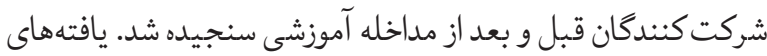

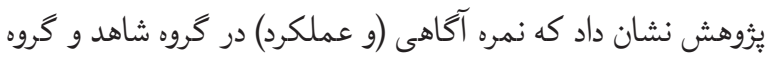
مداخله، هر دو يك ماه بعد از مداخله، افزايش معنادارى داشتند.

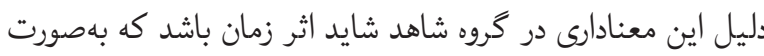
تجمعى منجر به افزايش آكاهى ايشان گرديده است. و نيز مى تواند

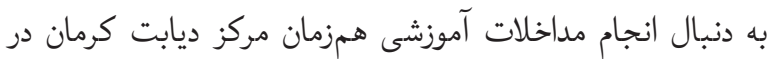

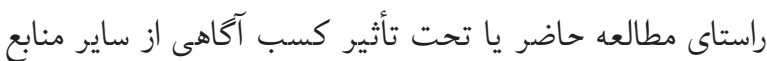
مانند رسانههاى گروهى، دوستان و آشنايان باشد.

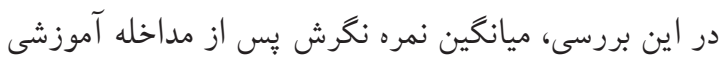

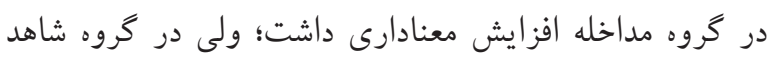

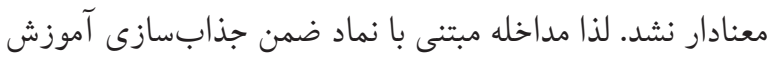
و تأثير بيشتر بر ياد كيرى مطلوب افراد تحت مطالعه، ظاهراً در

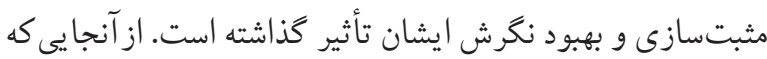
هر قدر نگرش شخص نسبت به يك رفتار مطلوبتر باشد،

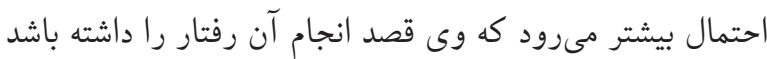

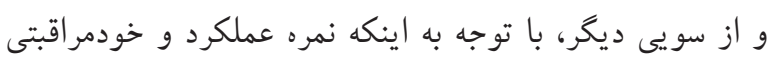

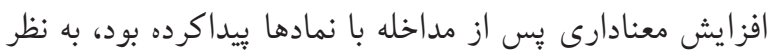

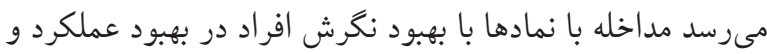

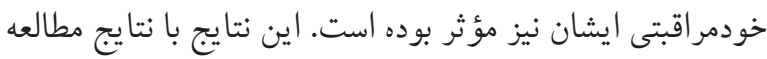

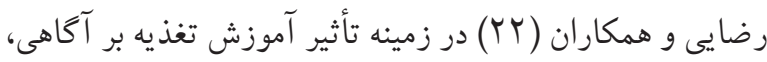
نكرش و عملكرد مبتلايان به ديابت در شهرستان اليخودرز

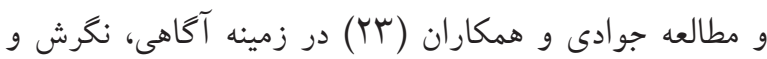
عملكرد بيماران ديابتى نسبت به بيمارى ديابت در شهر قزوين

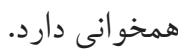
رفتار خودمراقبتى افراد ديابتى هم بهصورت كلى ود هم هم به

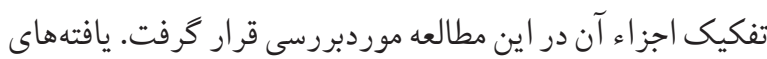


عواملى نظير سن، بِيجيدگى درمان، طول مدت بيمارى نيز بر

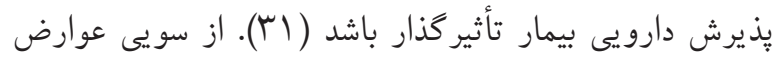

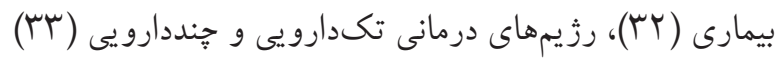

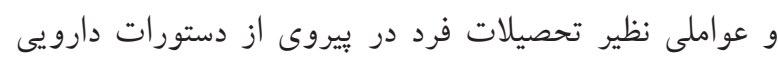

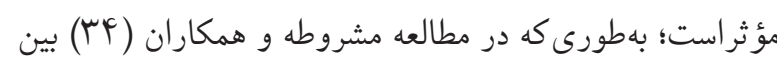

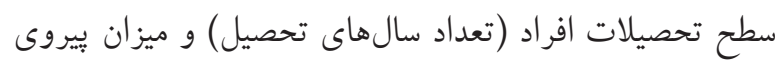
از دستورات دارويى ارتباط مثبتى وجود داشت.

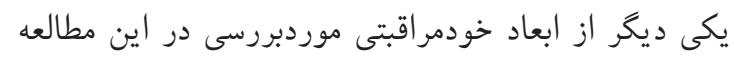

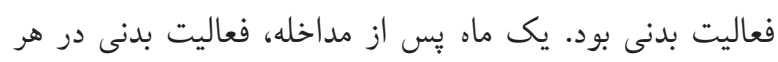

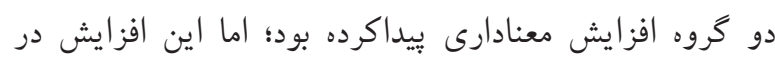

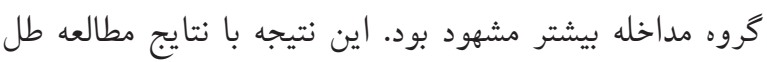

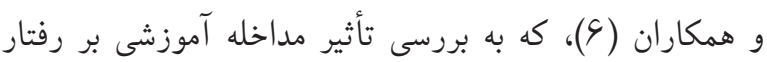

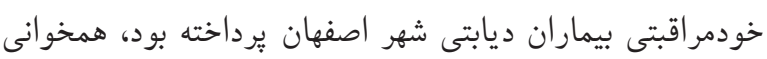

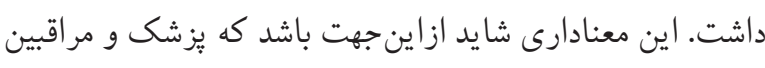

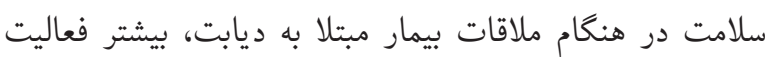
بدنى را مورد تأكيد قرار مىدهند ولى بهطور كامل به جزئيات

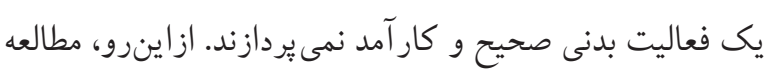
حاضر با آموزش جزئيات و جنبههاى صحيح فعاليت بدنى در دراني

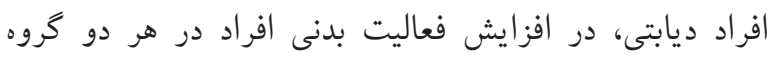

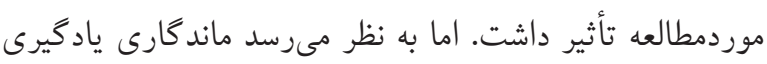

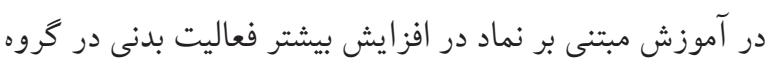

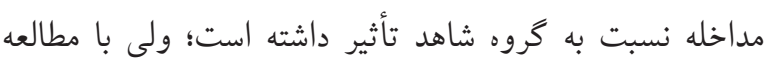

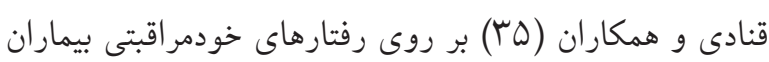
ديابتى خرم آباد همسو نيست. كنترل و پايش قند خون نيز در اين مطالعه در گروه مداخله

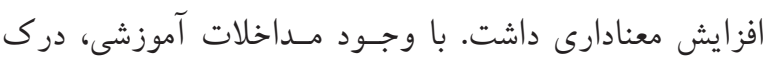

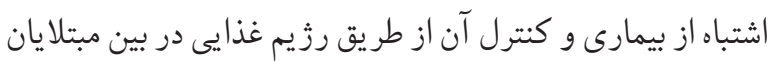
به ديابت امرى شايع است (צr)؛ اما اكر كاربرد خوديايشى قند خون با آموزشهاى صحيح همراه باشد، مى تواند عليرغم هز ينهبر

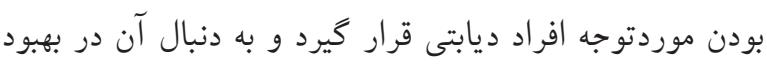

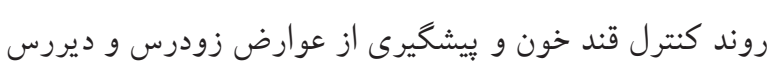

هزينه خاصى نياز ندارد، به نظر مىرسد ارائه آموزشها در اين

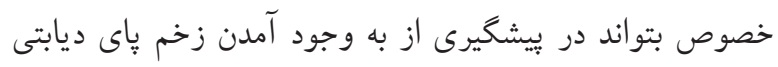

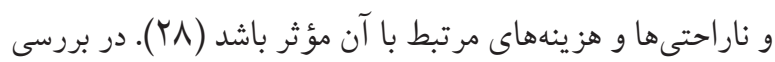

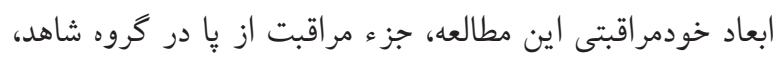

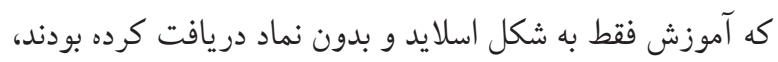
افزايش مختصرى داشت؛ كه به لحاظ آمارى معنادار نشد. اما در

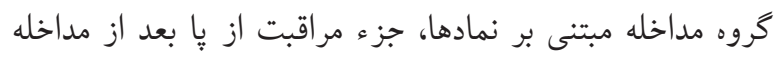

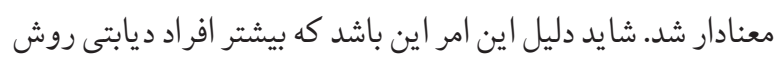

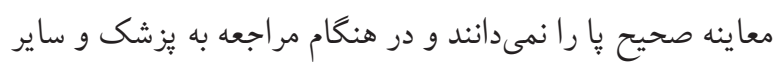

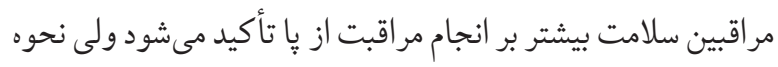

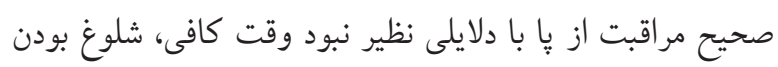

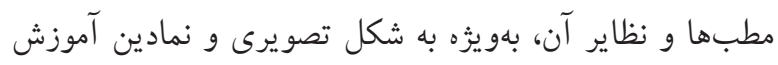

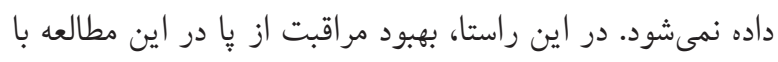

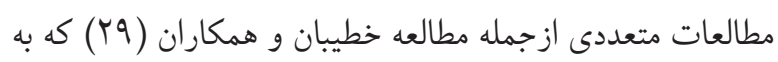

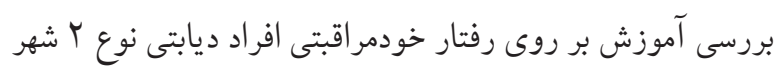

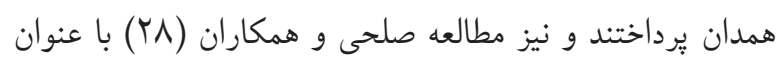

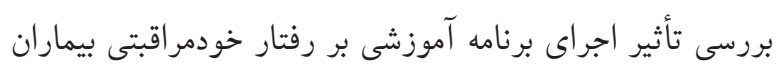
نوع ب شهرستان كُجساران همخوانى دارد.

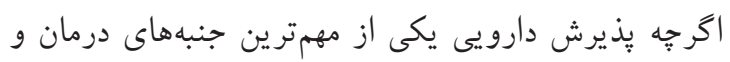

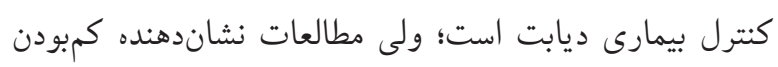

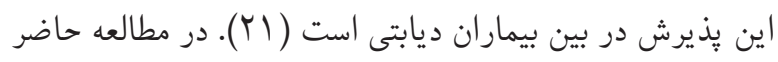

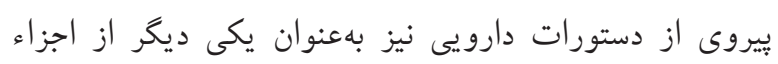

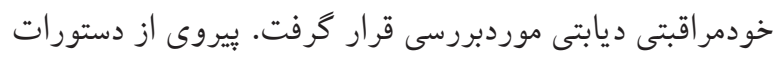

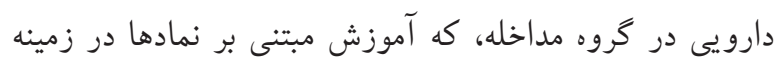

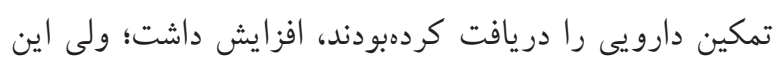

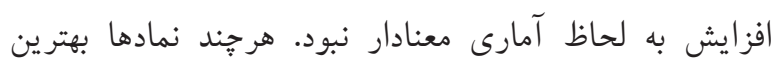

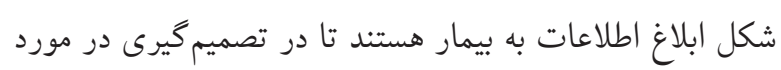

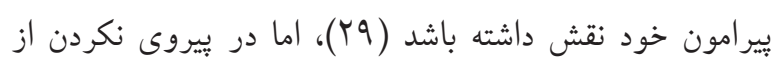

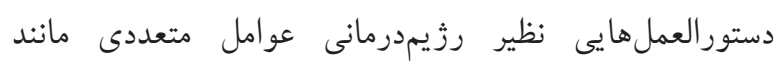
خصوصيات فردى بيماران، نظام مراقبت بهداشتى و رابطه متقابل

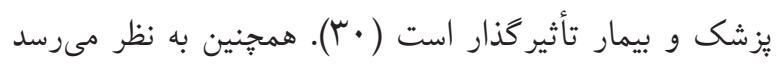


(TY)

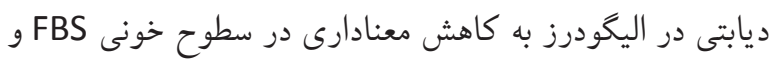
HbA1C اين مطالعه محدوديتهايى نيز داشت. محدود بودن زمان مطالعه بر روى بررسى دقيق برخى از اجزاء خودمراقبتى تأثير

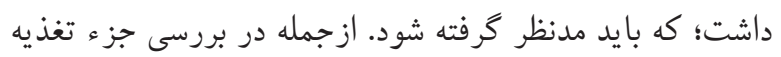

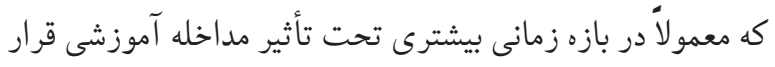

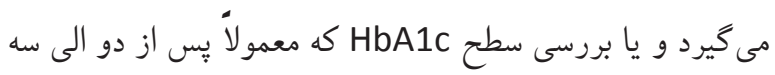

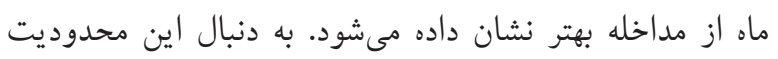
زمانى امكان سنجش شاخصهاى لييو بِروتئين يُروفايل نيز

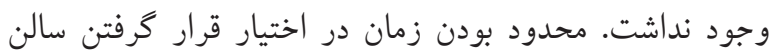
آموزش در ساعات ادارى نيز باعث شد كه شركت مردان، افراد تحصيل كرده، افراد شاغل و نيز افراد جوانتر به دليل مشغوليت تحصيلى يا شغلى كمتر باشد. از ديكر محدوديتهاى مطالعه

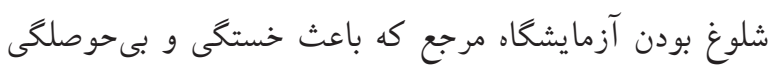

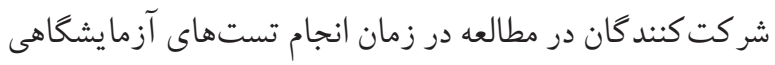

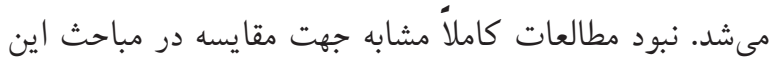

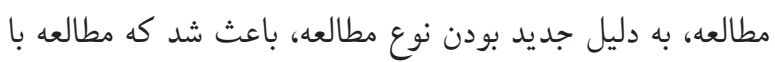
مطالعاتى كه مشابهت نسبى داشتند مورد مقايسه قرار گيرد.

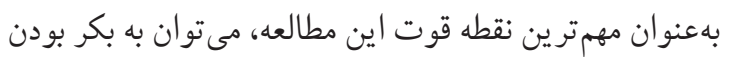

نسبى اين مطالعه در جامعه جهانى و نيز در ايران اشاره كرد.

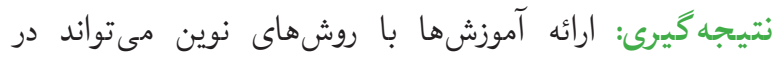
يادگيرى دستورالعملهاى بهداشتى و ارتقاء رفتارهاى بهداشتى بـى نورين بلهويزه در بيمارىهاى مزمن نقشى مؤثر داشته باشد. در اين ميان،

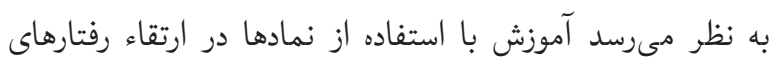

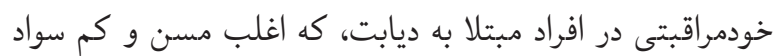
هستند، تأثيركذار باشد.

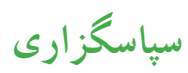
اين مطالعه، گزارش بخشى از پايانامه كارشناسىارشد مصوب

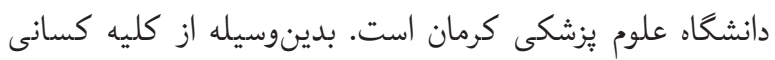
كه ما را در اين مطالعه يارى كردند، قدردانى مىشود.
ديابت مؤثر باشد. در اين راستا، مطالعه خطيبان و همكاران (rV)

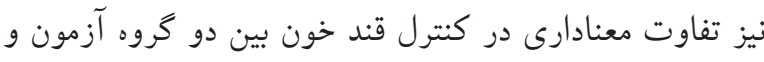
كنترل پِ از مداخله را نشان داد. استفاده از روشهاى تغذيهاى در كاهش عوارض، مشكلات

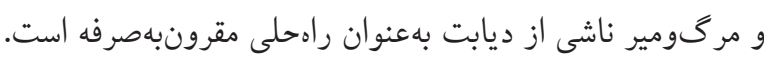

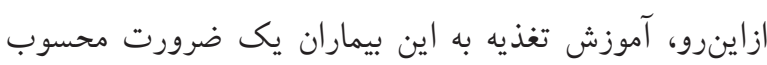

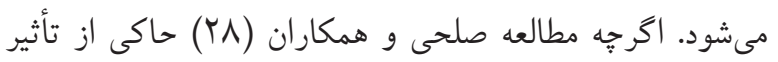

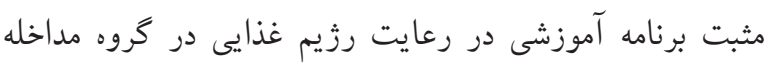

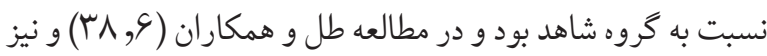

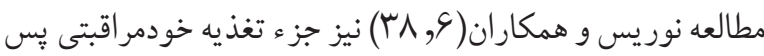
از مداخله بهبود معنادارى بيداكرده بود؛ اما در مطالعه حاضر رفتار خودمر اقبتى تغذيه پِ از مداخله تغيير معنادارى بيدا نكرد. هر جند

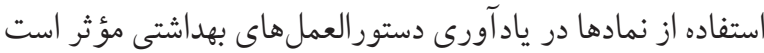

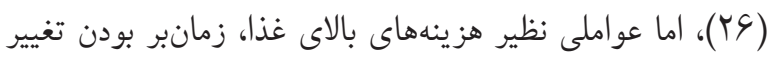

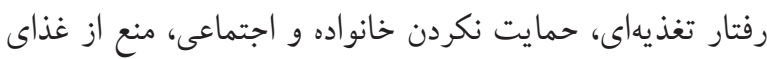

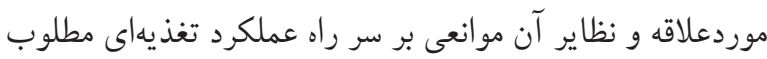

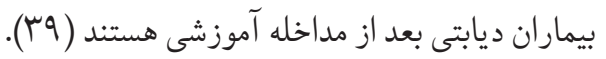

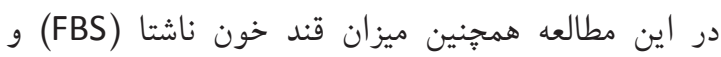

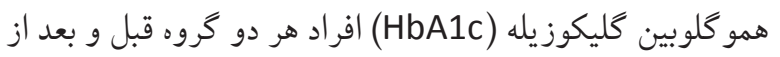
مطالعه اندازهكيرى شد. در بررسى سطوح خونى FBS و HbA1c

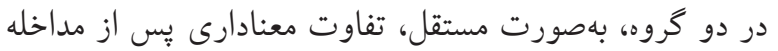
مشاهده نشد. ولى ميانكين كلى سطوح خونى FBS و HbA1c

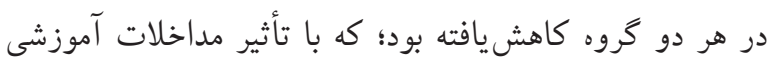
همخوانى دارد. اما جهت بررسى بيشتر ازنظر معنادارى مداخله

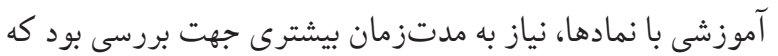

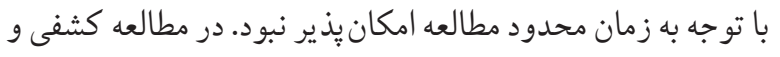

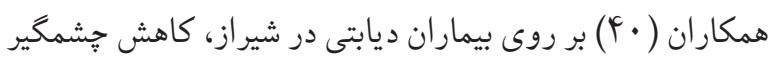

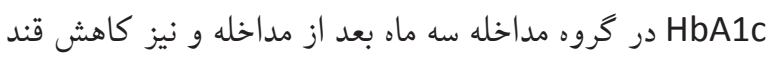
خون ناشتا مشاهده شد. مطالعه نجمى و همكاران ( أF) در اصفهان

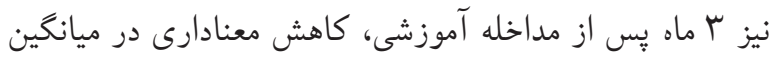

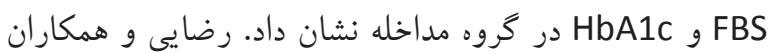




\section{References:}

1. Gonder-Frederick LA, Cox DJ, Ritterband LM, . Diabetes and behavioral medicine: the second decade. J Consult Clin Psychol. 2002;70(3):611-25.

2. http://www.who.int/en/. Global health risks. Mortality and burden of disease attributable to selected major risks. Geneva2009 [updated January2015].

3. Danaei G, Finucane M, Lu Y, Singh G, Cowan M, Paciorek $C$, et al. National, regional, and global trends in fasting plasma glucose and diabetes prevalence since 1980: systematic analysis of health examination surveys and epidemiological studies with 370 country-years and 2.7 million participants. Lancet. 2011;378(9785):31-40.

4. Kasper DL, Braunwald E, Fauci AS, Hauser SL, Longo DL, Jameson JL. Harrison's principles of internal medicine. 16th ed: Columbus OH: McGraw- Hill; 2005.

5. IDF. Diabetes Atlas. Brussels: International DiabetesFederation; 2011 [updated Last accessed 26 June 2012; cited 2013 /15/10];

:[Available at http://www.idf.org/diabetesatlas].

6. Tol A, Shojaeezadeh D, Sharifirad G, Alhani F. Effect of education program based on empowerment model in promoting self-care among type 2 diabetic patients in Isfahan. Razi Journal of Medical Sciences. 2013;20(107):18-31[persian].

7. Lin CC, Anderson RM, Chang CS, Hagerty BM, LovelandCherry CJ. Development and testing of the diabetes selfmanagement instrument: A confirmatory analysis

Res Nurs Health. 2008;31(4):370-80.

8. Peyman N, Ezzati-Rastgar K, Tehrani H. The Impact of Educational Intervention Based on PEN-3 Model on Oral Health Behavior in Elementary School Students. Iranian Journal of Health Education and Health Promotion. 2016;4(2):149-57. [persian].

9. Peimani M, TabatabaeiMalagheri O, Heshmat R, AmiriMoghadam S, Sanjari M, Pazhouhi M. physicians knowledge, attitude and practice on blood suger and lipid control among people with diabetes type 2 . J diabetes \& lipid of Iran. 2010;90(4):357-64[persian].

10. Goudarzi M, EbrahimZadeh E, Rabie A, SaeediPour B, AsghariJafarAbadi $M$. The relation between self- efficacy and knowledge, attitude and practice among people with diabetes type 2 in Karaj, Iran. J diabetes \& lipid of Iran. 2012;11(3):269-81[persian].

11. RakhshandeRu S, Ghaffari M, Heidarnia A, Rajab A. Influence of educational intervention on metabolic control among referring diabetic people to Diabetes Association of Iran. Special Journal of Risk Factors in Diabetes and Heart Disease; Diabetes \& lipid of Iran J. 2009:57-64[persian].

12. Osborn CY, Egede LE. Validation of an Informationâ $€^{\text {"Motiv }}$ ationâ€"Behavioral Skills model of diabetes self-care (IMB-
DSC). Patient education and counseling. 2010;79(1):49-54.

13. Ahadian M. Principles of Educational Technology. Tehran: Boshra Publication. 1993[persian].

14. Tait AR, Voepel-Lewis T, Zikmund-Fisher BJ, Fagerlin A. The Effect of Format on Parents' Understanding of the Risks and Benefits of Clinical Research: A Comparison between Text, Tables, and Graphics. J Health Commun. 2010 July;15(5):487-501.

15. Eslami A, Ahanchi N, Sharifirad G. Effects of Family-Based Theory of Social Support on Perceived Support Levels in Type 2 Diabetic Patients. Journal of Health System Research. 2012;8(5):757-64[persian].

16. AbootalebiDaryasari G, VosoghiKarkazloo N, Farahani B, Mohammadnezhad E, Sajjadi A. The study of self-care agency in patients with diabetes (Ardabil). Modern Care, Scientific Quarterly of Birjand Nursing and Midwifery Faculty. 2012;8(4):197-204[persian].

17. Choi J. Literature review: using pictographs in discharge instructions for older adults with low-literacy skills. Journal of Clinical Nursing. 2011;20(21-22):2984-96.

18. Toobert D, Hampson S, Glasgow R. The Summary of Diabetes Self-Care Activities Measure. DIABETES CARE. JULY2000;23(7):943-50.

19. Goudarzi M, EbrahimZadeh E, Rabie A, SaeediPour B, AsghariJafarAbadi $M$. The correlation between KAP and efficacy in patients with type 2 diabetes in Karaj, Iran. Iranian Journal of Diabetes and Lipid Disorders. 2012;11(3):269-81[persian].

20. Hasani M, Khanjani N, Mahmodi M, Fadakar M, Iranpour A, Gozashti M. Developing pictographs for increasing adherence in patients with diabetes mellitus. thesis. 2014[persian].

21. Hashem F, Karbakhsh M, Soheilikhah S, Sedaghat M. Drug compliance in patients with type 2 diabetes who were referred to hospitals in Shariati and Khomeini. Quarterly Monitoring Institute (SID). 2005;4(2):103-11[persian].

22. Rezaei N, Tahbaz F, Kimiagar M, Alavimajd H. The effect of nutrition education on knowledge, attitude and practice among people with type 1 diabetes. Shahrkord university of medical sciences. 2006;8(2):52-9[persian].

23. Javadi A, Javadi M, Sarvghadi F. The survey of knowledge, attitude \& practice about diabetes among people with diabetes type 2 in Bouali Sina Ghazvin, Iran. Birjand Journal of Medical Sciences. 2004;11(3):46-51[persian].

24. Mahmoodi H, Negarandeh R, Heshmat R. Comparison of impact of Pictorial and Teach-back educational strategies on knowledge, adherence to medication and diet among people with diabetes type 2 and low health literacy attending to diabetes unit of Imam Khomeini hospital in saqqez. Tehran: Tehran University of Medical Sciences; 2011[persian]. 
25. Houts PS, Bachrach R, Witmer JT, Tringali CA, Bucher JA, Localio RA. Using pictographs to enhance recall of spoken medical instructions. Patient education and counseling. 1998;35(2):83-8.

26. Houts PS, Witmer JT, Egeth HE, Loscalzo MJ, Zabora JR. Using pictographs to enhance recall of spoken medical instructions II. Patient education and counseling. 2001;43(3):231-42.

27. Saffari M, Shojaeizadeh D, Pakpour A, Sanaeinasab $H$. Educational Technology In Health Field. Tehran: Sobhan Asar; 2012[persian].

28. Solhi M, Jalilian F, ZinatMotlagh F. Effectiveness of Education Program on Increasing Self Management Among Patients with Type II Diabetes. Scientific Journal of Ilam University of Medical Sciences. 2012;20(1):26-34[persian].

29. Hawley ST, Zikmund-Fisher B, Ubel P, Jancovic A, Lucas $T$, Fagerlin A. The impact of the format of graphical presentation on health-related knowledge and treatment choices. Patient Education and Counseling. 2008;73:44855.

30. Hadi N, Rostami-Gorani N, Jafari P. A Study on the determining factors for compliance to prescribed medication by patients with high blood pressure. Sci Med J Ahwaz Jundishapur Univ Med 2005;4(3):223-9[persian].

31. Cramer J, Benedict A, Muszbek N, Keskinaslan A, Khan $Z$. The significance of compliance and persistence in the treatment of diabetes, hypertension and dyslipidaemia: a review. International journal of clinical practice. 2008;62(1):76-87.

32. Vinter-Repalust N, Jurković L, Katić $M$, Simunović R, Petric D. [Disease duration, patient compliance and presence of complications in diabetic patients]. Acta medica Croatica: casopis Hravatske akademije medicinskih znanosti. 2007;61(1):57-62.

33. Dailey G, Kim M, Lian J. Patient compliance and persistence with anti-hyperglycemic therapy: evaluation of a population of type 2 diabetic patients. Journal of international medical research. 2002;30(1):71-9.

34. Mashrouteh M, Khanjani N, Gozashti M. Evaluation of compliance with regimens in diabetic patients refrerred to the endocrinology clinic of Afzalipour hospital, Kerman, Iran. Journal of Health \& Development. 2012;1(3):182-92[persian].

35. Ghannadi K, Anbari K, Kaviani M, Montazari R. Self-Care and related factors in diabetic patients Khorramabad. Journal of Research University of Medical Sciences. 2012;4:49-53[persian].

36. MardaniHamuleh $M$, ShahrakiVahed $A$. The effect of education based on HBM on adherence to the diabetic diet. Iranian Journal of Diabetes and Lipid Disorders. 1390;9(3):268-75[persian].

37. Khatiban M, Oshvandi K, Jokar M, Keyani J, Yousefzadeh $M$, Sultanian A. The effect of self care education baesd on Teach Back method on promotion of self care behaviors in type2 diabetic patients: aclinical trail study. Iranian journal of Diabetes and Metabolism. 2014;13(2):131-44[persian].

38. Norris SL, Engelgau MM, Narayan KV. Effectiveness of self-management training in type 2 diabetes a systematic review of randomized controlled trials. Diabetes care. 2001;24(3):561-87.

39. Sharifirad G, Entezari M, Kamran A, Azadbakht L. Efficacy of nutrition education to diabetic patient: Application of health belief model. Iranian Journal of Diabetes and Lipid Disorders 2008;7:379-86[persian].

40. Kashfi S, Khanijyhouni A, Bahadorikhalili R, Hatami M. Evaluation of the Effects of Educating about Nutrition and Jogging on the Blood Sugar of Type II Diabetic Patients of a Clinic in Shiraz, Iran. Hakim Research Journal 2009;12(3):54-60[persian].

41. Najimi A, Sharifirad G, Hasanzadeh A, Azadbakht L. Effect of Nutrition Education on Nutritional Behaviors and Glycemic Control Indices Based on BASNEF Model among Elderly with Type 2 Diabetes. Journal of Isfahan Medical School. 2011;29(155):1247-58[persian]. 